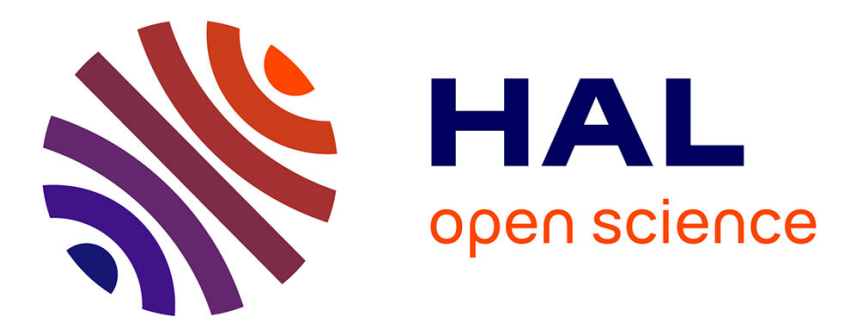

\title{
Linking the multiscale porous structure of hexacyanoferrate-loaded silica monoliths to their hydrodynamic and cesium sorption properties
}

Clément Cabaud, Yves Barré, Laurent de Windt, Agnès Grandjean

\section{- To cite this version:}

Clément Cabaud, Yves Barré, Laurent de Windt, Agnès Grandjean. Linking the multiscale porous structure of hexacyanoferrate-loaded silica monoliths to their hydrodynamic and cesium sorption properties. Separation and Purification Technology, 2019, 229, 10.1016/j.seppur.2019.115796 . hal02355605

HAL Id: hal-02355605

https://hal-mines-paristech.archives-ouvertes.fr/hal-02355605

Submitted on 25 Oct 2021

HAL is a multi-disciplinary open access archive for the deposit and dissemination of scientific research documents, whether they are published or not. The documents may come from teaching and research institutions in France or abroad, or from public or private research centers.
L'archive ouverte pluridisciplinaire HAL, est destinée au dépôt et à la diffusion de documents scientifiques de niveau recherche, publiés ou non, émanant des établissements d'enseignement et de recherche français ou étrangers, des laboratoires publics ou privés.

\section{(ㄷ)(1) $\$$}

Distributed under a Creative Commons Attribution - NonCommerciall 4.0 International 


\section{Linking the multiscale porous structure of hexacyanoferrate-loaded silica monoliths to their hydrodynamic and cesium sorption properties}

Clément Cabaud $^{\mathrm{a}, \mathrm{b}}$, Yves Barréa ${ }^{\mathrm{a}}$ Laurent De Windt ${ }^{\mathrm{b}}$, Agnès Grandjean*a

a. CEA, DEN, DE2D, SEAD, Laboratory of Supercritical and Decontamination Processes, Univ. Montpellier, F-30207 Bagnols-sur-Cèze, France.

b. MINES Paris Tech, PSL University, Centre de Géosciences, F-77300 Fontainebleau, France.

\section{Declarations of interest: none.}

\section{A B S T R A C T}

Multiscale porous silica monoliths functionalized with potassium/copper hexacyanoferrate (HCF) have been evaluated for the column extraction of cesium from natural water. Compared with commercial silica gel particles, results show that the hierarchically porous architecture of the monoliths improves the bed efficiency in column extraction, and the selectivity, distribution coefficient and exchange kinetics in batch extraction. Cesium breakthrough experiments show that these preferable properties of the monolithic structure are maintained in column operation. This analysis of the batch and breakthrough experiments is supported by scanning and transmission electron microscopy data, residence time distributions, and reactive transport modeling assuming dispersive flow in the macroporous intraskeletal channels and diffusion inside the walls of the structure and the HCF aggregates.

Keywords: Column process; Ferrocyanide; Hierarchical material; HYTEC; Ion exchanger. 


\section{Introduction}

Cesium-137 is considered to be one of the most hazardous fission products due to its presence in many effluents and wastes and its 30 years half-life. Therefore, its release can affect the environment for several decades. There is therefore substantial demand for effective, cost-efficient methods for $\mathrm{Cs}^{+}$ decontamination with a sorbent amenable to long-term disposal. A major difficulty for selective $\mathrm{Cs}^{+}$ extraction from effluents is competition with the alkali and alkaline earth ions found in natural waters. Transition metal hexacyanoferrates (HCF), analogues of Prussian blue, are insoluble ion-exchange compounds known to have a high affinity for cesium in aqueous solutions (whose speciation is usually the cation $\mathrm{Cs}^{+}$) over a wide range of pHs [1-3], salinity, and concentrations of competing cations [4-6] . They can be prepared by simple precipitation and can be used in bulk in solutions or in column processes after deposition on a solid substrate. This study focuses on a potassium HCF with copper as the transition metal because, with industrial applications in mind, copper is less toxic than nickel and less likely to be released in solution [7]. It has been shown furthermore that Prussian blue fragments released during $\mathrm{Cs}^{+}$extraction can be removed using an anion exchange process [8].

Porous silica was selected as the monolithic support for its high resistance to radiation damage, because its synthesis into multiscale structures is well understood [9], and because HCF-functionalized monoliths can be transformed by heat treatment into a final waste form that is convenient for long-term disposal [10]. The efficiency of silica monoliths is widely exploited in liquid and gas phase catalysis [9, 11-13] and they are also good candidate materials for column extraction processes [9, 14-16]. Their hierarchical porous structure makes them highly permeable and optimizes mass transport and they have more degrees of freedom for the design of fixed-bed columns than particulate materials. The latter are limited by their particle size and the requirement of mechanical stability under high pressure. In contrast, the macroporous channels in the monoliths ensure fast advective transport through the material with a well-defined residence time and little pressure drop, and the mesopores in the skeletal wall provide a large diffusion-accessible surface area and numerous active sites for functionalization. The higher mechanical strength of the monoliths makes them easier to handle and minimizes the risk of dispersion in the context of nuclear waste management. 
Almost all the in-flow experiments described in the literature for the extraction of $\mathrm{Cs}^{+}$from effluents involve particle-packed columns [17-21], with just one instance of monoliths being used [10]. Batch extraction using monolithic materials has been reported twice previously [10, 22]. This paper presents a detailed study of the extraction of cesium using HCF-functionalized monolithic materials that are effective in continuous processes. To emphasize the role of the porous structure of the columnpacking material, batch kinetics experiments were conducted using the $\mathrm{K} / \mathrm{Cu}-\mathrm{HCF}$-functionalized silica monolith crushed into grains or ground into a fine powder (to destroy the macropores), and with mesoporous silica grains functionalized with $\mathrm{K} / \mathrm{Cu}-\mathrm{HCF}$ in the same way. The column efficiency of the crushed monolithic material was then compared with equivalently sized and functionalized silica grains, and the hydrodynamics of the process with the two materials was characterized using residence time distributions (RTDs) measured with an inert tracer. Overall performance for cesium decontamination was evaluated using breakthrough experiments. Scanning and transmission electron microscopy (SEM and TEM) were used to build a multiscale model of the morphology of the monoliths for reactive transport modeling (RTM). This was used to fit the experimental data and obtain key parameters such as diffusion coefficients, as well as to support the proposed decontamination mechanism with the functionalized silica monoliths.

\section{Materials and methods}

\subsection{Chemicals and reagents}

All chemicals were purchased from Sigma Aldrich and used without further purification: tetraethyl orthosilicate (TEOS, reagent grade, 98\%), polyethylene oxide (PEO, molecular weight, $100 \mathrm{kDa}$ ), potassium ferrocyanide $\left(\mathrm{K}_{4} \mathrm{Fe}(\mathrm{CN})_{6} \cdot 3 \mathrm{H}_{2} \mathrm{O}\right)$, potassium nitrate $\left(\mathrm{KNO}_{3}\right)$, copper nitrate $\left(\mathrm{CuNO}_{3} .3 \mathrm{H}_{2} \mathrm{O}\right)$, cesium nitrate $\left(\mathrm{CsNO}_{3}\right)$. The solutions were prepared with pure water $(18 \mathrm{M} \Omega \cdot \mathrm{cm})$ or mineral water for the cesium sorption experiments. The total concentrations of the mineral water in competitive cations for $\mathrm{Cs}^{+}$exchange were: $\left[\mathrm{Na}^{+}\right]=2.8 \times 10^{-4} \mathrm{M},\left[\mathrm{K}^{+}\right]=2.6 \times 10^{-5} \mathrm{M},\left[\mathrm{Mg}^{2+}\right]=1.1 \times 10^{-3} \mathrm{M},\left[\mathrm{Ca}^{2+}\right]=2.0 \times 10^{-}$

${ }^{3} \mathrm{M}$. The $\mathrm{pH}$ and full composition of the mineral water are given in Table A.1 (supplementary data). Radiocesium solutions were prepared by dilution of a $40 \mathrm{kBq} \cdot \mathrm{mL}^{-1}$ standard of ${ }^{137} \mathrm{CsNO}_{3}$ in pure water. 


\subsection{Preparation of monolithic silica gel and functionalization with $H C F$}

Monolithic silica was synthesized via a sol-gel route with spinodal decomposition using a polymer as templating agent as first developed by Nakanishi [23] and adapted by Sachse [24]. The first step consisted in mixing PEO in a TEOS solution for 3 days at $40^{\circ} \mathrm{C}$. The microporous structure of the materials and the amount of polymer are governed by the kinetics of separation between the silica-rich and water-rich phases. The molar ratios with respect to $\mathrm{SiO}_{2}$ were 14.2, 0.60 and 0.28 for $\mathrm{H}_{2} \mathrm{O}$, ethylene oxide (monomer unit), and $\mathrm{HNO}_{3}$, respectively. The samples were then treated in a caustic ammonia solution (0.1 M), leading to Ostwald ripening and a disordered porous structure [24-27]. After washing, the final silica monoliths (length $=3 \mathrm{~cm}$; diameter $=0.9 \mathrm{~cm}$; mass $=0.5 \mathrm{~g}$ ) were obtained by calcination at $550^{\circ} \mathrm{C}$ in air for $6 \mathrm{~h}$.

The monoliths were wrapped in heat shrink polyolefin tubing and connectors at both end were sealed to the tubing with epoxy resin.to be used directly as a packing material for continuous column extraction. Functionalization was carried out in continuous flow using a protocol inspired by the one described previously by Michel et al. for silica beads [4]. After pretreating the surface of the silica pores with a $10^{-4} \mathrm{M} \mathrm{KOH}$ solution, the insoluble HCF was inserted into the pores using a two-step precipitation process. Typically, $40 \mathrm{~mL}$ of copper nitrate solution $(0.01 \mathrm{M})$ was eluted through the pretreated monolith for $20 \mathrm{~min}$ in a loop. The monoliths were then washed with deionized water to remove unattached copper and $40 \mathrm{~mL}$ of a mixed potassium ferrocyanide $(0.01 \mathrm{M})$ and potassium nitrate $(0.01 \mathrm{M})$ solution was percolated for $20 \mathrm{~min}$ at $8 \mathrm{~mL} \cdot \mathrm{min}^{-1}$ before a final wash in deionized water. This material is hereafter denoted HCF@ silica-monolith. A fraction of this material was subsequently ground into a fine powder (particle size $<20 \mu \mathrm{m}$ ) for batch sorption experiments. This material is denoted “powdered HCF@ silica-monolith”.

Pristine silica monoliths were also crushed into $250-500 \mu \mathrm{m}$ particles (Fig. 1a) and packed into a column before being functionalized in flow using the same process. This material is referred to as HCF@ crushed-silica-monolith.

Commercial silica gel (Sigma-Aldrich; particle size $=250-500 \mu \mathrm{m}$; average pore size $=15 \mathrm{~nm}$; 
Fig. 1b) was used as a reference silica support and was functionalized in the same way. This material is denoted HCF@silica-particles hereafter.
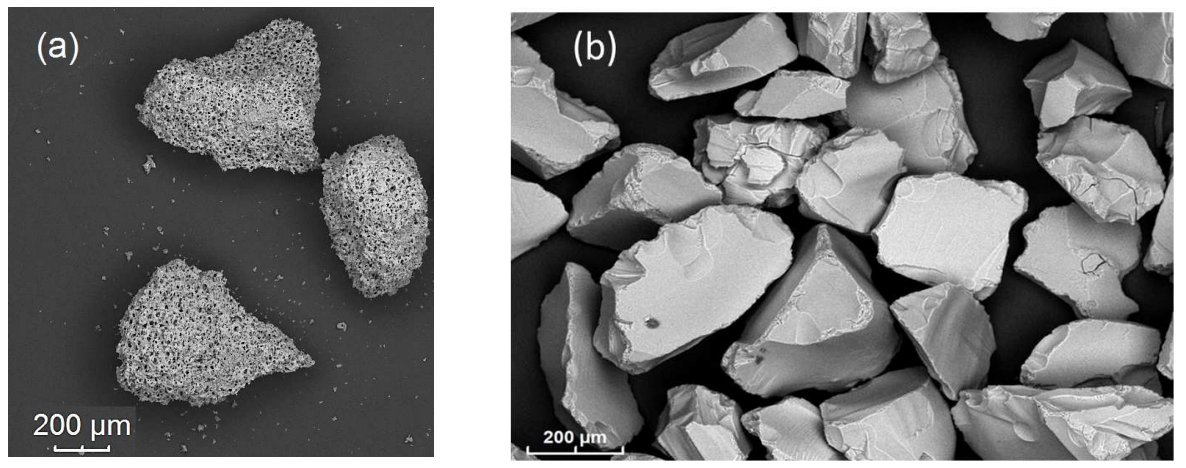

Fig. 1. Scanning electron micrographs of (a) crushed monolithic silica gel (200-500 $\mu \mathrm{m}$ in diameter) and (b) commercial silica gel particles (also 200-500 $\mu \mathrm{m}$ in diameter).

\subsection{Microstructural analysis}

Specific surface areas were calculated using the Brunauer-Emmet-Teller (BET) method from nitrogen adsorption isotherms measured with a Quantachrome NOVAtouch analyzer after degassing the samples for $12 \mathrm{~h}$ at $35^{\circ} \mathrm{C}$. Pore size distributions were determined using the Barret- Joyner-Halenda (BJH) method. The microstructure of the samples was observed using a Tescan - Mira3 scanning electron microscope with a Bruker - X Flash detector 530 energy dispersive X-ray (EDS) detector and a Zeiss Leo EM 910 transmission electron microscope.

\subsection{Batch sorption experiments}

Sorption tests were carried out in batch mode with samples of powdered HCF@ silica-monolith, HCF@crushed-silica-monolith and HCF@silica-particles to correlate their sorption kinetics and porous structure. The powder samples $(100 \mathrm{mg})$ were suspended with vigorous magnetic stirring in $100 \mathrm{~mL}$ of mineral water (Table A.1) containing $3.9 \times 10^{-4} \mathrm{~mol} \cdot \mathrm{L}^{-1}$ of $\mathrm{Cs}^{+}$added by dissolution of $\mathrm{CsNO}_{3}$. At different times, $2 \mathrm{~mL}$ samples were collected with a syringe, filtered through a $0.45 \mu \mathrm{m}$ membrane, and analyzed by atomic adsorption spectrometry (Perkin Elmer AAnalyst 400).

To measure complete sorption isotherms, $100 \mathrm{mg}$ samples were suspended with vigorous magnetic stirring in $100 \mathrm{~mL}$ of $\mathrm{Cs}^{+}$-containing mineral water for $24 \mathrm{~h}$, which was sufficient to reach equilibrium. The equilibrium concentrations range from $1.5 \times 10^{-13} \mathrm{~mol} \cdot \mathrm{L}^{-1}\left({ }^{137} \mathrm{Cs}^{+}\right)$to $1.3 \times$ 
$10^{-3} \mathrm{~mol} \cdot \mathrm{L}^{-1}\left({ }^{133} \mathrm{Cs}^{+}\right)$

The sorption mechanism can be described as the following. $\mathrm{Cs}^{+}$cations in solution first percolate through the porosity and then be exchanged with the mobile ions $\mathrm{K}^{+}$from $\mathrm{HCF}$ :

$$
\bar{K}^{+}+C s^{+} \leftrightarrow K^{+}+\overline{C S}^{+}
$$

The sorption capacity $\left(Q, \mathrm{~mol} \cdot \mathrm{g}^{-1}\right)$ of the materials was calculated using Eq. (2):

$$
Q=\frac{V}{m}\left(\left[\mathrm{Cs}^{+}\right]_{0}-\left[\mathrm{Cs}^{+}\right]\right)
$$

where $V(\mathrm{~L})$ is the volume of the solution, $m(\mathrm{~g})$, the mass of the solid sample, and $\left[\mathrm{Cs}^{+}\right]_{0}$ and $\left[\mathrm{Cs}^{+}\right]$ $\left(\mathrm{mol} \cdot \mathrm{L}^{-1}\right)$ are respectively the initial and remaining concentrations of $\mathrm{Cs}^{+}$in the solution.

The $\mathrm{Cs}^{+}$distribution coefficient $\left(K_{d, \mathrm{Cs}}, \mathrm{mL} \cdot \mathrm{g}^{-1}\right)$ was calculated as follows,

$$
K_{d, \mathrm{Cs}}=\frac{\overline{\left[\mathrm{Cs}^{+}\right]}}{\left[\mathrm{Cs}^{+}\right]_{\mathrm{eq}}} \times 1000
$$

with $\overline{\left[\mathrm{Cs}^{+}\right]}$is the concentration of $\mathrm{Cs}^{+}$in the solid $\left(\mathrm{mol} \cdot \mathrm{g}^{-1}\right)$ and $\left[\mathrm{Cs}^{+}\right]_{\mathrm{eq}}$ the equilibrium concentration of $\mathrm{Cs}^{+}$in the solution $\left(\mathrm{mol} \cdot \mathrm{L}^{-1}\right)$.

\subsection{Residence time distribution experiments}

Residence time distributions were measured by injecting a pulse of $\mathrm{NaNO}_{3}$ tracer $(1.17 \times$ $\left.10^{-1} \mathrm{M}\right)$ in deionized water $(18 \mathrm{M} \Omega \cdot \mathrm{cm})$ into a column (monolithic, filled with a silica monolith, or fixed bed, filled with the commercial silica particles or crushed silica monolith) and monitoring the $\mathrm{Na}^{+}$ concentration at the outlet. The measurements were performed with non-functionalized samples to avoid the potential release of HCF nanoparticles, which could have clogged the detector capillaries, and any ionic exchange between the K/Cu HCF and $\mathrm{Na}$ ions. The monolithic and fixed-bed columns had the same dimensions (length $=3 \mathrm{~cm}$; diameter $=0.9 \mathrm{~cm})$ and bed volume $(1.89 \mathrm{~mL})$. The injection loop was $100 \mu \mathrm{L}$ and the volumetric flow rate was $0.7 \mathrm{~mL} \cdot \mathrm{min}^{-1}$, corresponding to a Darcy velocity $(U)$ of 0.8 $\mathrm{m} \cdot \mathrm{h}^{-1}$. The electrical conductivity of the flow was monitored in-line using a Metrohm 850 ion chromatograph.

The distribution function, $\mathrm{E}(\mathrm{t})$, was obtained by normalizing the concentration of the nonreactive tracer at the outlet, $\mathrm{C}_{\text {out }}(\mathrm{t})[28]$ : 


$$
E(t)=\frac{C_{\text {out }}(t)}{\int_{0}^{\infty} C_{\text {out }}(t) d t}
$$

The mean residence time, $\overline{t_{s}}$, is equal to the first moment of the RTD [28]:

$$
\overline{t_{s}}=\mu_{1}=\int_{0}^{\infty} t E(t) d t
$$

This can be compared with the ideal residence time, $\tau$, which is a function of "the volumetric flow rate $\left(Q_{V}\right)$ and the connected porosity (macroporosity) of the monolith or bed $(\varepsilon)$ :

$$
\tau=\frac{V_{\text {column }} \cdot \varepsilon}{Q_{v}}
$$

Identical values of $\bar{t}_{\mathrm{s}}$ and $\tau$ indicate that the column is functioning ideally, without geometrical defects such as dead volumes or preferential flow pathways.

The flow porosity can be calculated by subtracting the volume of the silica walls, assumed to be pure dense silica $\left(\rho_{\mathrm{Si}}=2.65 \mathrm{~kg} \cdot \mathrm{L}^{-1}\right)$ and the mesoporous volume (obtained from nitrogen adsorption isotherms) from the total volume of the column $\left(V_{\text {column }}\right)$ :

$$
\varepsilon=\frac{V_{\text {column }}-\left(\frac{m_{\text {column }}}{\rho_{\mathrm{Si}}}+V_{\text {mesoporous }}\right)}{V_{\text {column }}}
$$

Assuming axially-dispersed plug flow, the distribution function can be expressed in terms of the dispersion Péclet number (Pe) [29]:

$$
E(t)=\frac{1}{2} \sqrt{\frac{P e}{\pi \cdot \bar{t}_{s} \cdot t}} \exp \left[-\frac{P e\left(\bar{t}_{s}-t\right)^{2}}{4 \cdot \bar{t}_{s} \cdot t}\right]
$$

The Péclet number is the ratio of the rates of advection and diffusion and is obtained by fitting. The higher $P e$ is, the closer the column is to an ideal reactor, with $P e \geq 100$ indicating ideal plug flow behavior.

The permeability of the bed $\left(k, \mathrm{~m} \cdot \mathrm{s}^{-1}\right)$ can be obtained from the pressure drop $(\Delta P, \mathrm{~Pa})$ using the Darcy law [30],

$$
U=\frac{k}{\mu} \frac{\Delta P}{L}
$$

where $U$ is the Darcy velocity $\left(\mathrm{m} \cdot \mathrm{s}^{-1}\right), \mu(\mathrm{Pa} \cdot \mathrm{s})$ is the dynamic viscosity of the fluid, and $L$ is the length of the bed. 


\subsection{Cesium breakthrough curves}

The shape of a breakthrough curve indicates how efficient the bed is at extracting $\mathrm{Cs}^{+}$under flow. The bed efficiency (BE) can be quantified as follows [10, 31]:

$$
\mathrm{BE}=\frac{\int_{V=0}^{V_{R}}\left(\left[\mathrm{Cs}^{+}\right]_{i}-\left[\mathrm{Cs}^{+}\right]_{\text {out }}\right) d V}{V_{\mathrm{R}} *\left[\mathrm{Cs}^{+}\right]_{i}}
$$

where $\left[\mathrm{Cs}^{+}\right]_{i}$ and $\left[\mathrm{Cs}^{+}\right]_{\text {out }}$ are the $\mathrm{Cs}^{+}$concentrations at the inlet and the outlet of the column, respectively. The retention volume $\left(V_{\mathrm{R}}\right)$ is the volume at which the outlet concentration is equal to half the inlet concentration for a symmetrical breakthrough, i.e. the point of inflexion of the curve. Thus, the $\mathrm{BE}$ corresponds to the proportion of the total amount of $\mathrm{Cs}^{+}$that has percolated through the column at half-breakthrough that is adsorbed by the bed. The higher the BE is, the steeper the breakthrough curve and the more efficient the decontamination process are. The breakthrough experiments were performed at a constant flow rate of $8.8 \mathrm{~mL} \cdot \mathrm{min}^{-1}$ corresponding to a linear (Darcy) velocity of $8 \mathrm{~m} \cdot \mathrm{h}^{-1}$. The inlet concentration of $\mathrm{Cs}^{+}$was set to $2.65 \times 10^{-4} \mathrm{~mol} \cdot \mathrm{L}^{-1}\left(35.4 \mathrm{mg} \cdot \mathrm{L}^{-1}\right)$, using the same mineral water solution as for the batch tests. The outflow of the column was divided in $8 \mathrm{~mL}$ fractions for analysis. A diagram of the experimental setup is shown in Fig. 2.

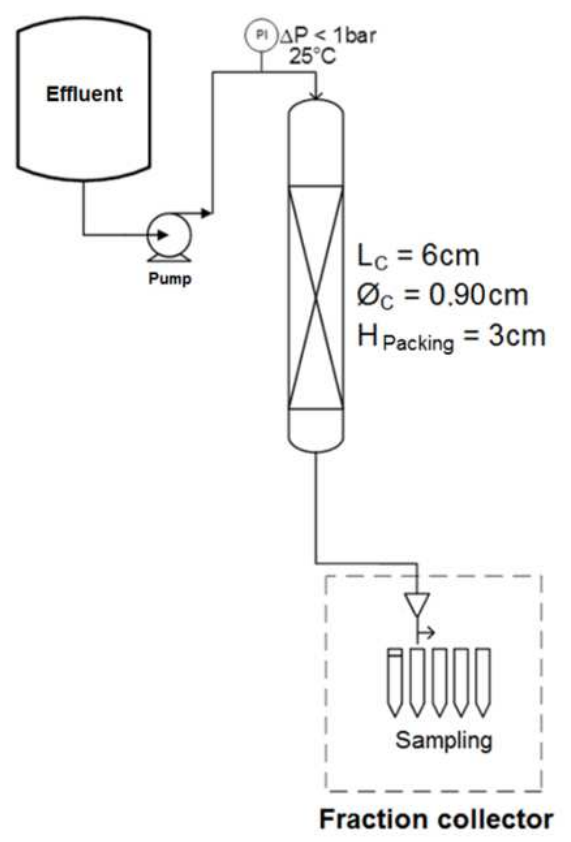

Fig. 2. Schematic diagram of the experimental setup used for the breakthrough experiments. 


\subsection{Reactive transport modeling}

Reactive transport modeling (RTM) is a powerful tool to estimate parameters such as diffusion coefficients inside porous structures and to extrapolate the model fit to a given dataset to other experimental conditions. Reactive transport in the batch and column experiments performed with HCF@ silica-monolith was modeled with HYTEC [32]. The general HYTEC formulation of the multicomponent reactive transport equation is [32]

$$
\frac{\partial \varepsilon C_{i}}{\partial t}=\nabla \cdot\left(D_{d} \nabla C_{i}-C_{i} U\right)-\frac{\partial \varepsilon \bar{C}_{l}}{\partial t}
$$

where $C_{i}$ and $\bar{C}_{l}$ are respectively the mobile and immobile concentrations of an element $i$ per unit volume of solution, $\varepsilon$ is the porosity of the material, and $U$ is the Darcy velocity. The partial derivative term

$-\frac{\partial \varepsilon \overline{C_{l}}}{\partial t}$ is driven by chemical reactions whereas the other terms represent transport processes. The term $D_{d}$ is the effective diffusion/dispersion coefficient [32],

$$
D_{d}=D_{e}+\alpha U
$$

which depends on the dispersivity, $\alpha$, the Darcy velocity, and the effective diffusion coefficient, $D_{e}$ ( $D_{e}=\varepsilon D_{p}$ where $D_{p}$ is the pore diffusion coefficient).

Aqueous acid/base and complexation reactions were modeled using the EQ3/6 thermodynamic database [33]. The cation exchange reactions were modeled at equilibrium using the Vanselow formalism (molar fraction approach) and the selectivity coefficients measured by Michel et al. for $\mathrm{K} / \mathrm{Cu}-$ HCF-functionalized silica particles [4]. As such, Cs/K exchange (Eq. 1) can be modeled but also the competitive effects of the cations of the mineral water (i.e. $\mathrm{K}^{+}, \mathrm{Na}^{+}, \mathrm{Ca}^{2+}$ and $\mathrm{Mg}^{2+}$ ).

\section{Results and discussion}

\subsection{Morphology and specific surface area of the sorbents}

Fig. 3a illustrates the three steps in the functionalizing process for a silica monolith and the corresponding changes in color (white to blue after adding copper, and then blue to brown after HCF is attached). Fig. 3b shows SEM images of the HCF@ silica-monolith material, with a typical sponge-like morphology consisting of $15 \mu \mathrm{m}$ channels (macropores, Fig. 3c), and $20 \mu \mathrm{m}$ walls. 
Fig. $3 \mathrm{c}$ also shows the $\sim 100 \mathrm{~nm}$ scale HCF particle aggregates deposited across the surface of the walls. The TEM image in Fig. 3d shows an aggregate of HCF nanoparticles $~ 100 \mathrm{~nm}$ and 5-10 nm particle units. The EDX map of a polished cross section of the material set in epoxy resin after $\mathrm{Cs}^{+}$exchange (Fig. 4) highlights the presence of HCF nanoparticles on the surface of the structure but also, in smaller quantities, in the mesopores inside the walls. The Cs map (Fig. 4d) confirms the presence of cesiumexchanged $\mathrm{HCF}$ in the skeletal wall and, therefore, the involvement of this deeper population in $\mathrm{Cs}^{+}$ exchange.
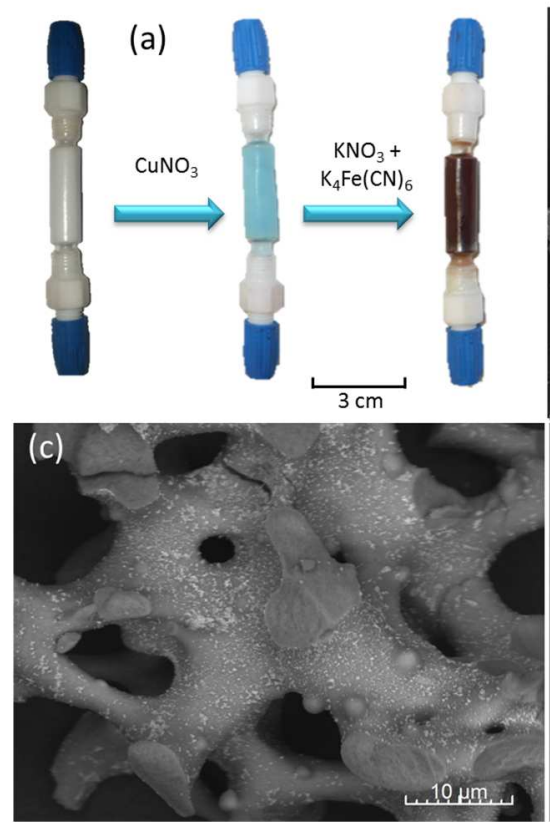

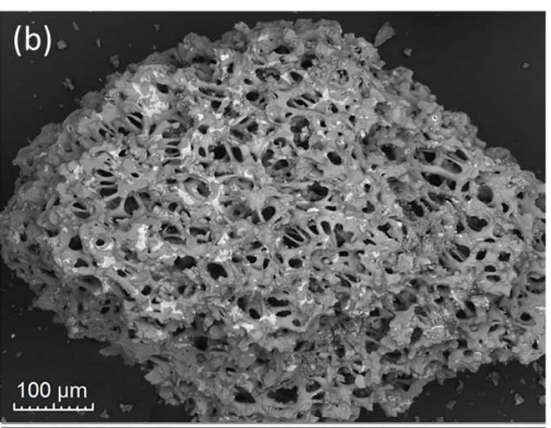

(d)

Fig. 3. Hierarchical porous silica monolith functionalized with $\mathrm{Cu} / \mathrm{K}$ hexacyanoferrate (HCF@ silica-monolith): (a) photographs of a monolith at different stages of the functionalizing process, (b) scanning electron micrograph of the macroporous network, (c) scanning electron micrograph of HCF aggregates deposited on the surface of the skeletal walls, and (d) transmission electron micrograph of an aggregate of HCF nanoparticles. 


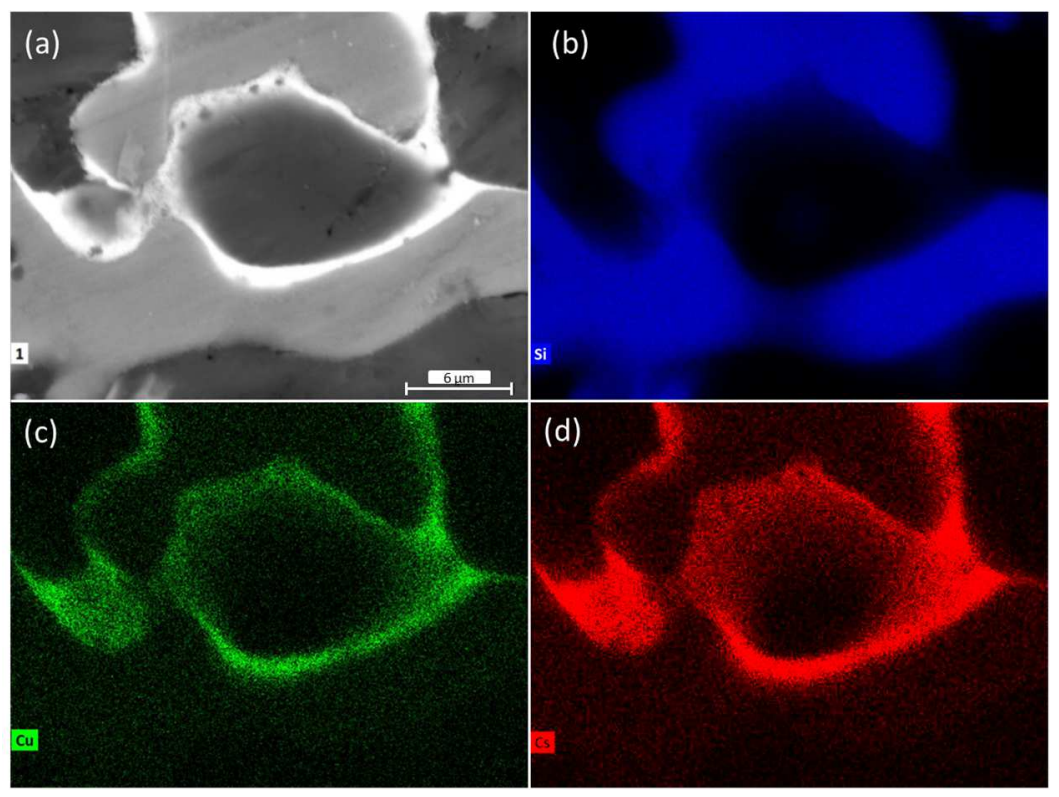

Fig. 4. (a) Scanning electron micrograph of a polished cross section of a $\mathrm{Cu} / \mathrm{K}$-hexacyanoferrate-functionalized silica monolith (HCF@ silica-monolith) after a cesium sorption experiment and (b-d) corresponding energy-dispersive X-ray maps for silicon (blue), copper (green) and cesium (red).

No HCF aggregates were observed by SEM on the surface of the silica particles in the HCF@ silica-particles sample (data not shown) and the EDX map in Fig. 5 shows that potassium (from the $\mathrm{Cu} / \mathrm{K}-\mathrm{HCF}$ particles) is homogeneously distributed in a depth-independent fashion throughout the silica particles, indicating that the HCF@ silica-particles material is entirely porous.

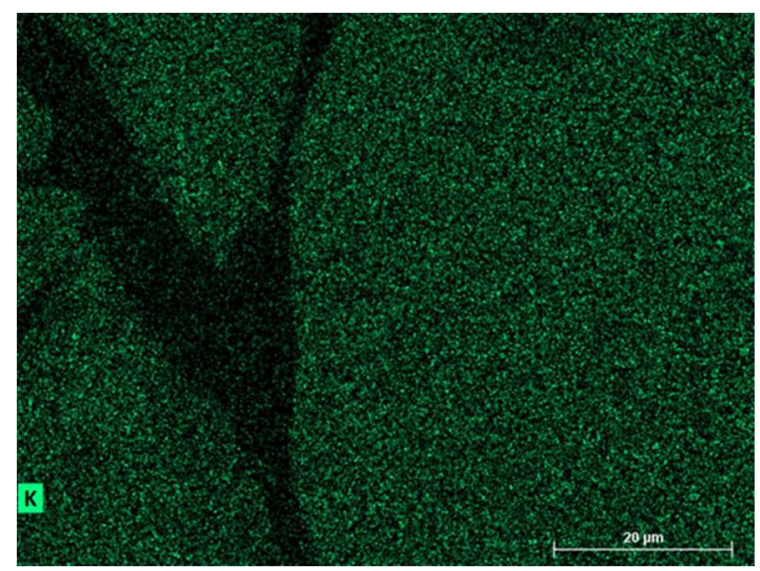

Fig. 5. Energy-dispersive X-ray map of potassium (in green) in a polished cross section of a packed sample of commercial silica gel particles functionalized with $\mathrm{Cu} / \mathrm{K}$ hexacyanoferrate set in epoxy resin.

The $\mathrm{N}_{2}$-adsorption isotherms measured for the monolith and the commercial silica particles (Fig. 
A.1) highlight their large porous volume and specific surface area. The insertion of $\mathrm{Cu} / \mathrm{K}-\mathrm{HCF}$ particles inside the porous materials leads to a decrease in their specific surface area (from 725 to $336 \mathrm{~m}^{2} \cdot \mathrm{g}^{-1}$ for the monoliths and from 339 to $310 \mathrm{~m}^{2} \cdot \mathrm{g}^{-1}$ for the commercial particles), which nonetheless remains high. The pores become partially obstructed: the porosity decreases from 1.08 to $0.77 \mathrm{~cm}^{3} \cdot \mathrm{g}^{-1}$ at $\mathrm{P} / \mathrm{P}_{0}=1$ for the monolithic material, where $\mathrm{P}$ and $\mathrm{P}_{0}$ are the pressure and the equilibrium vapor pressure of nitrogen, respectively, and from 1.11 to $1.03 \mathrm{~cm}^{3} \cdot \mathrm{g}^{-1}$ for the commercial particles. The flow porosities obtained using (7) from the nitrogen adsorption data are 0.61 for HCF@ silica-monolith, and 0.73 and 0.58 for packed samples of HCF@ crushed-silica-monolith and HCF@ silica-particles, respectively.

\subsection{Reactive transport model of the monolith}

The SEM data indicate that the silica monoliths consist of three structural elements (Fig. 6):

- Macroporous channels with a width of $15 \mu \mathrm{m}$ and a porosity equal to 1 . These were assumed to be uniformly distributed in the monoliths. The diffusion coefficient inside this channel was taken to be the same as for free water [34].

- Mesoporous skeletal walls with a width of $10 \mu \mathrm{m}$ and a porosity equal to 0.73 .

- Aggregates of HCF particles deposited on the surface of the mesoporous walls and inside the pores.

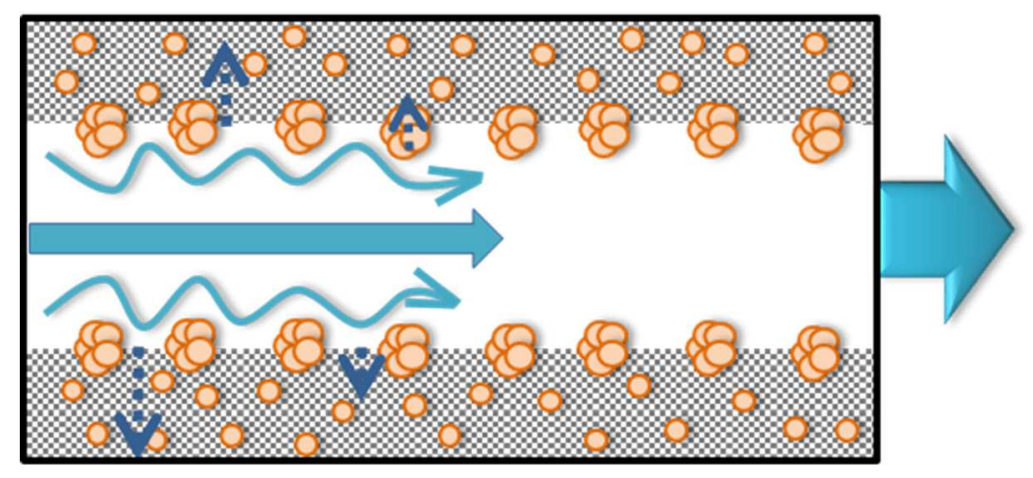

Fig. 6. Simplified model of reactive transport for $\mathrm{Cs}^{+}$in a macroporous channel in silica monoliths functionalized with hexacyanoferrate nanoparticles (orange circles); the dispersion inside the macroporous channel is derived from the dispersion of the monolithic structure. 
The transport mechanisms simulated were advection-dispersion through the channels with lateral diffusion into the mesoporous walls loaded with $\mathrm{HCF}$, and diffusion from the channel to the HCF aggregates on the surface of the walls. Similar models were used by Liapis et al. [35] for singlecomponent adsorption in a monolith with a biporous structure of approximately cylindrical channels through a mesoporous skeleton, and by Zabka et al. [36] to study the adsorption and breakthrough of organic molecules in mesoporous monolithic columns.

The RTM grid used for the flow experiments is shown in Fig. 7. The particles of powdered HCF@ silica-monolith were represented by a thin slice in contact with the solution (Fig. A.2), with a realistic ratio between the mass of the monolith and the volume of water. The aggregates were represented by a fictitious continuous porous area with a width of $2.5 \mu \mathrm{m}$. The porosity of this area was arbitrarily set to 0.5 and the diffusion coefficient $\left(4 \times 10^{-10} \mathrm{~m}^{2} \cdot \mathrm{s}^{-1}\right)$ was adjusted to fit the kinetics data (section 3.3). The diffusion of $\mathrm{Cs}^{+}$ions from the channel to the aggregates was decoupled from their diffusion inside the skeletal wall, just as in the real system, by placing the aggregate area at the top and the skeletal wall at the bottom of the grid with the microporous channel in between. The X (length) and $\mathrm{Y}$ (thickness) dimensions of the grid mesh were $100 \mu \mathrm{m}$ and $2.5 \mu \mathrm{m}$, respectively. A boundary condition of constant flow velocity (Neumann condition) was set at the left-hand side of the interskeletal channel leading to a constant flux of the input solution. The constant flow velocity was greater than the Darcy velocity to compensate the fact that advection did not occur in the aggregate and skeletal wall. Zero flux conditions were set along the axial/ longitudinal boundaries (length direction) of the grid. Pure (deionized) water inside the whole monolith porosity and HCF exchangers $100 \%$ loaded in potassium were set as initial chemical conditions. Table 1 lists the parameters used to model reactive transport in the HCF@ silica-monolith experiments. Most parameters were measured or observed experimentally; for instance, the mean channel diameter and thickness of the skeletal walls were determined by SEM. The fractions of the maximum sorption capacity $\left(Q_{\max }\right)$ assigned to the HCF in the pores and on the surface of the skeletal walls was adjusted to correctly simulate the kinetics data (section 3.3). The full chemical composition of the mineral water was used, including competing cations for $\mathrm{Cs}^{+}$sorption. 


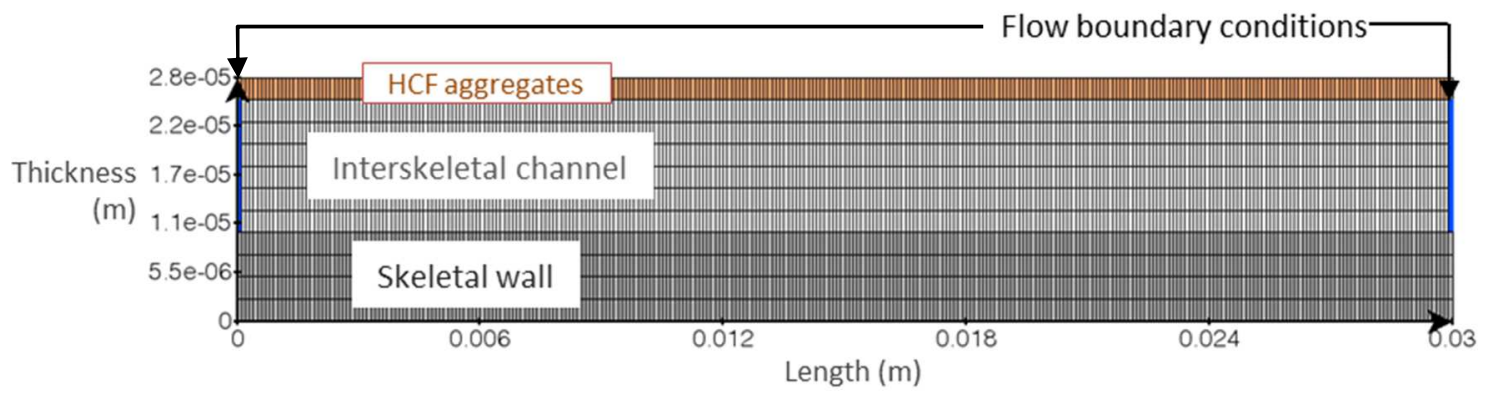

Fig. 7. Modeling grid used for the reactive transport of $\mathrm{Cs}^{+}$ions in silica monoliths functionalized with $\mathrm{Cu} / \mathrm{K}$ hexacyanoferrate nanoparticles (HCF@silica-monolith); the dispersion of solute transport in the channel was fitted from the RTD experiments to take into account the tortuosity of the silica monolith; diffusion was only allowed in the aggregate and skeletal wall.

\section{Table 1}

List of reactive transport modeling parameters used for pristine and powdered silica monoliths functionalized with $\mathrm{Cu} / \mathrm{K}$ hexacyanoferrate nanoparticles (HCF@silica-monolith and powdered HCF@silica-monolith).

\begin{tabular}{|c|c|c|c|}
\hline Region & Parameter & Value & Source \\
\hline \multirow{7}{*}{ Macroporous channel } & Length (m) & $\begin{array}{l}3.0 \times 10^{-2} \\
30 \times 10^{-6}\end{array}$ & $\begin{array}{l}\text { Column length }{ }^{\mathrm{a}}(\text { section } 2.5) \\
\text { Mean powder particle size }{ }^{\mathrm{b}}(\text { section } 2.4)\end{array}$ \\
\hline & Width (m) & $15 \times 10^{-6}$ & Scanning electron microscopy (section 3.1) \\
\hline & Porosity & 1 & Model assumption (section 3.2) \\
\hline & $D_{p}\left(\mathrm{~m}^{2} \cdot \mathrm{s}^{-1}\right)$ & $1 \times 10^{-9}$ & Free diffusion in water \\
\hline & $D_{e}\left(\mathrm{~m}^{2} \cdot \mathrm{s}^{-1}\right)$ & $1 \times 10^{-9}$ & $D_{e}=$ porosity $\times D_{p}$ \\
\hline & $\alpha(\mathrm{m})$ & $2 \times 10^{-4}$ & Fit of residence time distribution data (section 3.4 ) \\
\hline & $\mathrm{k}\left(\mathrm{m}^{2}\right)$ & $4 \times 10^{-12}$ & Experimental data (section 3.4) \\
\hline \multirow{6}{*}{ Skeletal wall } & Length (m) & $\begin{array}{l}3.0 \times 10^{-2} \\
30 \times 10^{-6}\end{array}$ & $\begin{array}{l}\left.\text { Column lengtha }{ }^{\text {a }} \text { (section } 2.5\right) \\
\text { Mean powder particle sizeb (section } 2.4)\end{array}$ \\
\hline & Width (m) & $10 \times 10^{-6}$ & Scanning electron microscopy (section 3.1) \\
\hline & Porosity & 0.73 & Experimental data (section 3.1) \\
\hline & $D_{p}\left(\mathrm{~m}^{2} \cdot \mathrm{s}^{-1}\right)$ & $4 \times 10^{-11}$ & Fit of kinetics data (section 3.3) \\
\hline & $D_{e}\left(\mathrm{~m}^{2} \cdot \mathrm{s}^{-1}\right)$ & $3 \times 10^{-11}$ & $D_{e}=$ porosity $\times D_{p}$ \\
\hline & $Q_{\max }$ fraction & 0.40 & $\begin{array}{l}Q_{\max } \text { measured experimentally (section 3.3.3), } \\
\text { fraction fitted to kinetics data (section 3.3) }\end{array}$ \\
\hline \multirow{6}{*}{ Surface HCF aggregates } & Length (m) & $\begin{array}{l}3.0 \times 10^{-2} \\
30 \times 10^{-6}\end{array}$ & $\begin{array}{l}\text { Column lengtha }(\text { section } 2.5) \\
\text { Mean powder particle size }{ }^{\mathrm{b}}(\text { section } 2.4)\end{array}$ \\
\hline & Width (m) & $2.5 \times 10^{-6}$ & Scanning electron microscopy (section 3.1) \\
\hline & Porosity & 0.50 & Experimental data (section 3.1) \\
\hline & $D_{p}\left(\mathrm{~m}^{2} \cdot \mathrm{s}^{-1}\right)$ & $4 \times 10^{-10}$ & Fit of kinetics data (section 3.3) \\
\hline & $D_{e}\left(\mathrm{~m}^{2} \cdot \mathrm{s}^{-1}\right)$ & $2 \times 10^{-10}$ & $D_{e}=$ porosity $\times D_{p}$ \\
\hline & $Q_{\max }$ fraction & 0.60 & $\begin{array}{l}Q_{\max } \text { measured experimentally (section 3.3.3), } \\
\text { fraction fitted to kinetics data (section 3.3) }\end{array}$ \\
\hline
\end{tabular}

aValue used to model the residence time distribution and the breakthrough experiments.

bValue used to model the batch experiments. 


\subsection{Sorption kinetics}

\subsubsection{Comparison of the porous silica materials}

Sorption kinetics were measured for the HCF@ silica-particles, HCF@crushed-silica-monolith and powdered HCF@ silica-monolith materials; the grinding of the monolith into a fine powder eliminated the macroporous channels, leaving diffusion in the mesopores or within the HCF aggregates as the only transport mechanism. The amount of sorbed cesium was normalized with respect to the sorption capacity at $24 \mathrm{~h}$ for each material and plotted versus the square root of time to expand the scale for shorter times (Fig. 8). Cesium uptake was very fast for all three functionalized materials. Table 2 lists the time required to reach $Q_{\max }$ (the equilibration time), the sorption capacity at $60 \mathrm{~s}$, and the time to half-maximum sorption capacity for the three materials. The material with the fastest sorption kinetics was powdered HCF@ silica-monolith. This is likely because the fine grinding (particle size $<20 \mu \mathrm{m}$ ) ensured that the microporous channels $(10 \mu \mathrm{m}$ wide) were almost completely eliminated, bringing cesium immediately into contact with the HCF aggregates on the surface of the skeletal walls. The HCF is distributed in the same way in HCF@crushed-silica-monolith but since the particles are larger (300$500 \mu \mathrm{m}$ across), they still contain macroporous channels that increase the diffusion path length. The initial steepness of the curve can be explained by the effect of the small fraction of HCF particles on the edges of the HCF@ crushed-silica-monolith particles. With HCF@ silica-particles, since the HCF is located on the inside of the material, the extraction process is delayed by the time required for cesium to diffuse into the particles; the initial sorption kinetics are thus slower than for the monolithic materials. Overall however, $Q_{\max }$ is reached faster with HCF@silica-particles than with HCF@crushed-silicamonolith.

These results highlight the influence of the porous structure of these materials on their sorption kinetics, as predicted by recent mesoscale phase-field modeling [37]. A previous study on a material similar to HCF@ silica-particles showed that $90 \%$ of the sorption occurred within 5 min [4]. A similar timescale was also observed for the sorption kinetics of $\mathrm{NaCu}-\mathrm{HCF}-$ modified $\mathrm{Fe}_{2} \mathrm{O}_{3}$ nanoparticles, for which $97.5 \%$ of the maximum adsorption capacity was reached within 2 min [38]. With Ni-HCF loaded onto a dense $\mathrm{Zr}(\mathrm{OH})_{4}$ substrate in contrast, it took 4 days to reach $85 \%$ of $Q_{\max }$ [39]. 


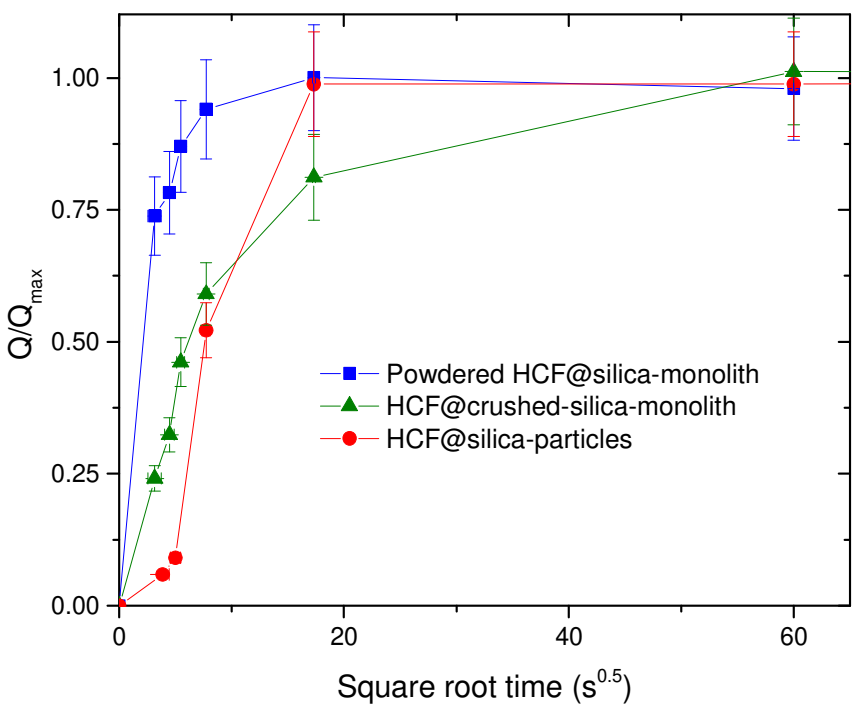

Fig. 8. Sorption kinetics of crushed and powdered silica monoliths functionalized with $\mathrm{Cu} / \mathrm{K}$ hexacyanoferrate nanoparticles (respectively HCF@crushed-silica-monolith, 300-500 $\mu \mathrm{m}$ in size, green triangles; and powdered HCF@ silica-monolith, <20 $\mu \mathrm{m}$ particle size, blue squares) and commercial silica gel particles functionalized in the same way (HCF@silica-particles, $250-500 \mu \mathrm{m}$ in size, red circles) in mineral water $\left(\left[\mathrm{Cs}^{+}\right]=3.9 \times 10^{-4} \mathrm{~mol} \cdot \mathrm{L}^{-1}\right)$. (Lines are guide for the eyes)

Table 2

Cesium sorption kinetics in mineral water

\begin{tabular}{lcccc}
\hline Material & $\begin{array}{c}\text { Equilibration time } \\
(\mathrm{s})\end{array}$ & $\begin{array}{c}Q_{\max } \\
\left(\mathrm{mol} \cdot \mathrm{g}^{-1}\right)\end{array}$ & $\begin{array}{c}\mathrm{t}_{\mathrm{Q}_{\max } / 2} \\
(\mathrm{~s})\end{array}$ & $\begin{array}{c}Q_{60 \mathrm{~s}} \\
\left(\mathrm{~mol} \cdot \mathrm{g}^{-1}\right)\left[\% Q_{\mathrm{max}}\right]\end{array}$ \\
\hline Powdered HCF@silica-monolith & $60<t<300$ & $5.6 \times 10^{-5}$ & 3.2 & $5.4 \times 10^{-5}[94]$ \\
HCF@crushed-silica-monolith & $300<t<3600$ & $5.6 \times 10^{-5}$ & 37 & $3.3 \times 10^{-5}[59]$ \\
HCF@silica-particles & $60<t<300$ & $1.9 \times 10^{-4}$ & 53 & $9.9 \times 10^{-5}[52]$ \\
\hline
\end{tabular}

$Q, \mathrm{Cs}^{+}$sorption capacity; $\mathrm{HCF}, \mathrm{Cu} / \mathrm{K}$ hexacyanoferrate

\subsubsection{Modeling of sorption kinetics for the functionalized silica monoliths}

Fig. 9 shows RTM fits of the experimental $\mathrm{Cs}^{+}$sorption kinetics of powdered HCF@ silicamonolith at a $\mathrm{Cs}^{+}$concentration representative of the breakthrough experiments (about $4 \times 10^{-4} \mathrm{~mol} \cdot \mathrm{L}^{-1}$ ) and at a trace concentration of ${ }^{137} \mathrm{Cs}^{+}$. The optimal values of the diffusion coefficient $\left(D_{p}\right)$ in the mesh walls were found to be $4 \times 10^{-11} \mathrm{~m}^{2} \mathrm{~s}^{-1}$ and $4 \times 10^{-10} \mathrm{~m}^{2} \mathrm{~s}^{-1}$, respectively, assuming a lower sorption capacity in the silica walls $\left(0.4 \times Q_{\max }\right)$ than in the HCF aggregates $\left(0.6 \times Q_{\max }\right)$. The model data suggest that the kinetics are slightly faster at trace concentrations, but this could not be verified experimentally because the sorption process is extremely rapid in both cases. 


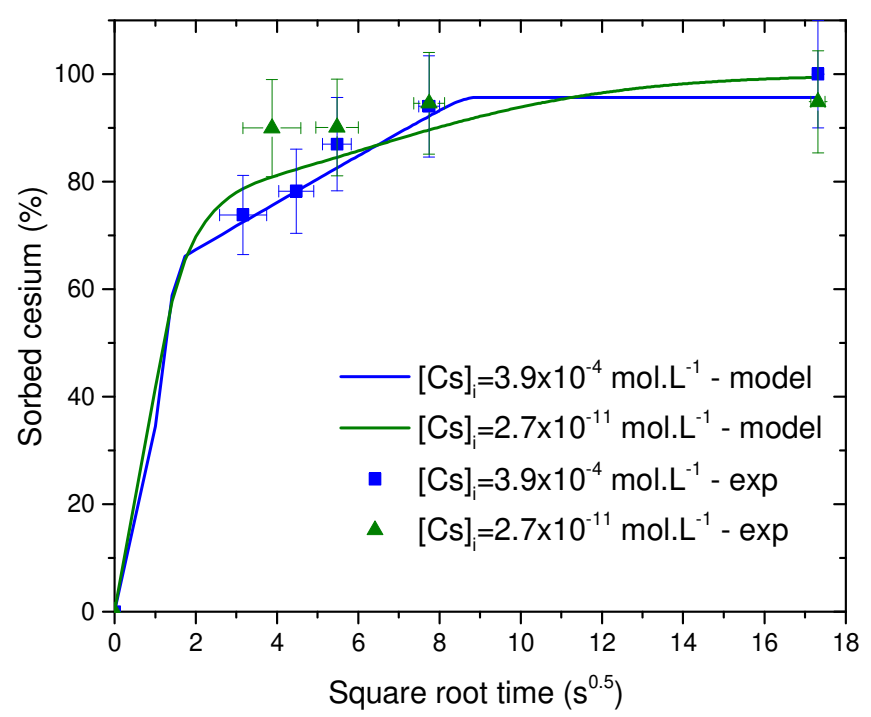

Fig. 9. Reactive transport modeling (Figs. 7 and A.2, Table 1) of the sorption kinetics of powdered silica monoliths functionalized with $\mathrm{Cu} / \mathrm{K}$ hexacyanoferrate nanoparticles (powdered $\mathrm{HCF} @$ silica-monolith) for $\mathrm{Cs}^{+}$in mineral water at $3.9 \times 10^{-4} \mathrm{~mol} \cdot \mathrm{L}^{-1}\left({ }^{133} \mathrm{Cs}^{+}\right.$, blue $)$and at a trace concentration $\left({ }^{137} \mathrm{Cs}^{+}\right.$, green $)$. The experimental data are shown as points with error bars.

\subsubsection{Sorption isotherms for the functionalized silica monoliths}

Fig. 10 shows the experimental and RTM isotherms for powdered HCF@ silica-monolith. It can be assumed that the same values would have been obtained for HCF@ silica-monolith considering the HCF population fully available. The dissociation constant $\left(K_{\mathrm{d}}\right)$ increases as the $\mathrm{Cs}^{+}$concentration at equilibrium decreases from $10^{-2}$ to $10^{-7} \mathrm{~mol} \cdot \mathrm{L}^{-1}$. At the lowest concentrations (with ${ }^{137} \mathrm{Cs}^{+}$) the experimental $K_{\mathrm{d}}$ plateaus at $5.0 \times 10^{5} \mathrm{~mL} \cdot \mathrm{g}^{-1}$, a value in agreement with the maximum $K_{\mathrm{d}, \mathrm{Cs}}$ of $10^{4}-10^{5}$ $\mathrm{mL} \cdot \mathrm{g}^{-1}$ reported previously for Prussian blue and other HCF materials [40]. The model reproduces the experimental data accurately for $\mathrm{Cs}^{+}$concentrations in the range $10^{-2}-10^{-7} \mathrm{~mol} \cdot \mathrm{L}^{-1}$ but underestimates the plateau value at the lowest concentrations by an order of magnitude. This is possibly because processes that are not included in the model, such as adsorption at defect sites, become important at trace concentrations. A similar gap between experimental and modeling results at trace concentrations has been reported previously for HCF-functionalized silica particles by Michel et al. [4]. 


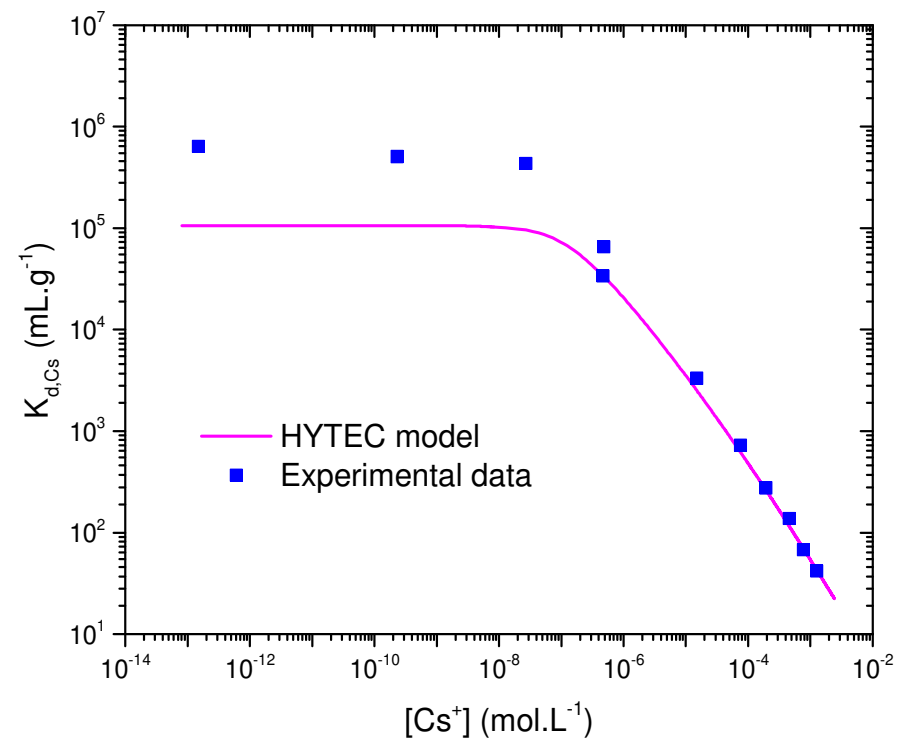

Fig. 10. Experimental (blue squares) and modeled (magenta line) dissociation constants for $\mathrm{Cs}^{+}$in mineral water as a function of the equilibrium $\mathrm{Cs}^{+}$concentration for powdered silica monoliths functionalized with $\mathrm{Cu} / \mathrm{K}$ hexacyanoferrate nanoparticles (powdered HCF@ silica-monolith).

\subsection{Column hydrodynamics}

\subsubsection{Comparison of the porous silica materials}

Fig. 11 compares the RTDs of columns packed with a silica monolith, crushed silica monolith, and commercial silica gel particles. Table 3 lists the RTD parameters obtained by fitting these data using (8). In all cases, the mean residence time $\left(\overline{t_{s}}\right)$ is slightly shorter than the ideal residence time. This systematic underestimation by about $10 \%$ probably reflects some delay of the RTD tracer by diffusion inside the skeletal walls of the monolith or inside the silica particles that is not taken into account by Eq. (8). This difference was neglected for the rest of the analysis and $t_{s}$ was taken to be equal to $\tau$. The Péclet number varies from 17 for the silica particles to 27 for the silica monolith, indicating that advection predominates over dispersion. The axial dispersivity due to the capillaries in the experimental setup, evaluated by measuring a RTD without a column, was found to be close to $1 \times 10^{-4} \mathrm{~m}$. The axial dispersivity ( $\alpha=L / \mathrm{Pe}$ ) of the columns accounting for this blank value ranged from $6 \times 10^{-4} \mathrm{~m}$ for the silica monolith to $9.5 \times 10^{-4} \mathrm{~m}$ for the commercial silica particles. Both the Péclet number and the axial dispersivity coefficient indicate that the flow was the least dispersive in the monolith. The commercial 
silica particles formed the most dispersive system probably because they are more irregular and thus packed less tightly than the crushed silica monolith particles, for which intermediated values were obtained. All three materials have a high permeability (Eq. (9), Table 1), with little pressure loss. According to a recent study of the relationship between permeability and pore size in mesoporous silica monoliths [26], a permeability of $4.0 \times 10^{-12} \mathrm{~m}^{2}$ corresponds to macropore diameters of between 8 and $14 \mu \mathrm{m}$ (in agreement with our SEM observations).

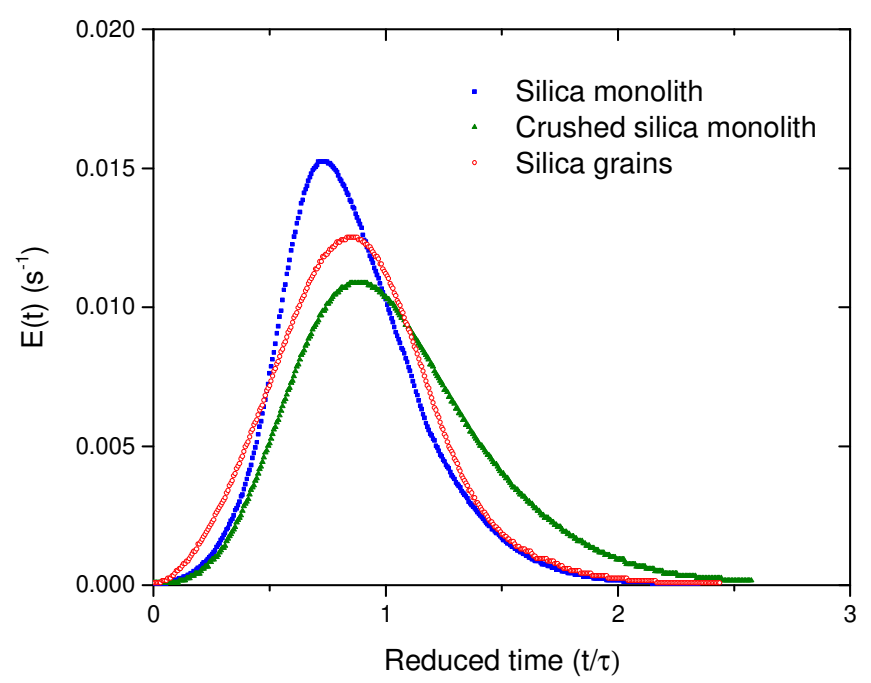

Fig. 11. Residence time distributions measured for columns packed with a silica monolith (blue), crushed silica monolith (green), and commercial silica gel particles (red) at a Darcy velocity of $0.8 \mathrm{~m} \cdot \mathrm{h}^{-1}\left(\left[\mathrm{NaNO}_{3}\right]_{0}=10.0 \mathrm{~g} \cdot \mathrm{L}^{-1}\right)$.

\section{Table 3}

Hydrodynamic parameters calculated from experimental residence time distributions or the pressure drop in the column.

\begin{tabular}{lccccc}
\hline Material & $\begin{array}{c}\text { Mean residence } \\
\text { time }(\mathrm{s})\end{array}$ & $\begin{array}{c}\text { Ideal residence } \\
\text { time }(\mathrm{s})\end{array}$ & $\begin{array}{c}\text { Peclet } \\
\text { number }\end{array}$ & $\begin{array}{c}\text { Axial } \\
\text { dispersivity }(\mathrm{m})\end{array}$ & $\begin{array}{c}\text { Permeability } \\
\left(\mathrm{m}^{2}\right)\end{array}$ \\
\hline Silica monolith & 83 & 97 & 27 & $6.0 \times 10^{-4}$ & $4.0 \times 10^{-12}$ \\
Crushed silica monolith & 100 & 118 & 19 & $8.5 \times 10^{-4}$ & $1.7 \times 10^{-11}$ \\
Commercial silica gel particles & 85 & 94 & 17 & $9.5 \times 10^{-4}$ & $1.8 \times 10^{-11}$ \\
\hline
\end{tabular}

\subsubsection{Modeling of residence time distributions for the silica monoliths}

Fig. 12 shows RTDs measured for pristine silica monoliths measured at flow rates of 0.8 to $4.8 \mathrm{~m} \cdot \mathrm{h}^{-1}$ and the corresponding distributions obtained by RTM. A control calculation carried out with a more refined grid confirmed the absence of numerical dispersion in the RTM results. All the simulations were performed with the same dispersivity coefficient of $2 \times 10^{-4} \mathrm{~m}$, which is slightly lower than the 
value $\left(6 \times 10^{-4} \mathrm{~m}\right)$ derived from the experimental data assuming ideal plug flow in a homogeneous column without diffusion in the walls of the monolith. Conversely, if diffusive mass transfer is suppressed in the reactive transport model, the experimental RTDs are best reproduced with a dispersivity coefficient of $8 \times 10^{-4} \mathrm{~m}$. This RTM thus confirms the existence of diffusion in the monolithic mesh walls.

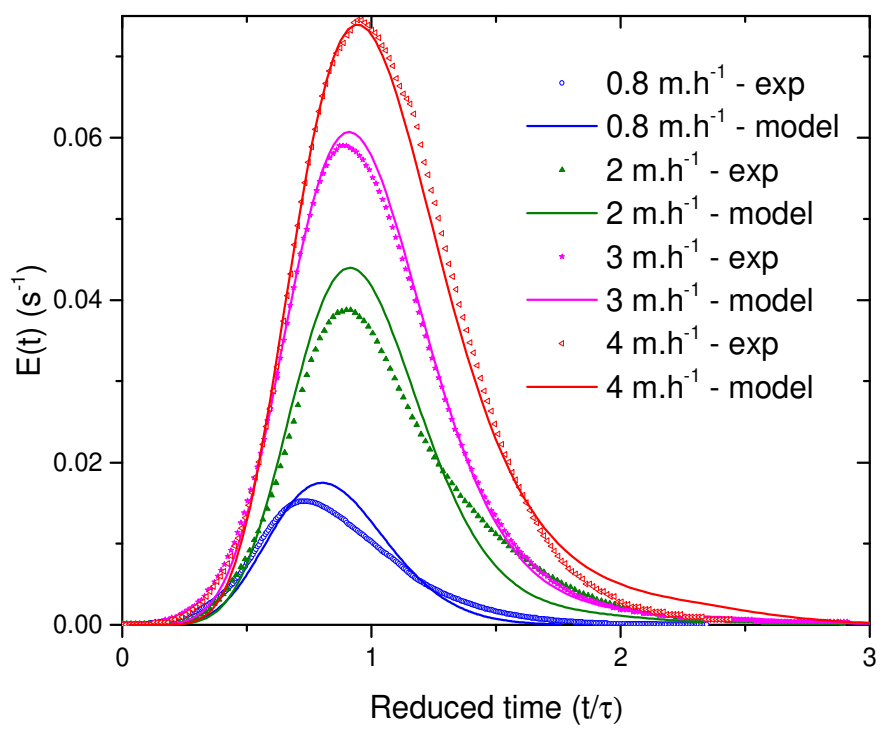

Fig. 12. Residence time distributions (time normalized to the ideal residence time) measured for silica monoliths at increasing Darcy velocities and the corresponding best fits calculated by reactive transport modeling (Figs. 7, Table 1).

\subsection{Cesium breakthrough curves}

\subsubsection{Comparison of the porous silica materials}

Fig. 13a compares the $\mathrm{Cs}^{+}$breakthrough curves measured at $8 \mathrm{~m} \cdot \mathrm{h}^{-1}$ for $\mathrm{HCF} @$ silica-monolith, HCF@crushed-silica-monolith and HCF@ silica-particles and the parameters obtained from the curves as defined in section 2.6 are listed in Table 4. Since the column dimensions were kept constant, the masses of each sorbent used differed. The $K_{\mathrm{d}}$ is proportional to the $\mathrm{Cs}^{+}$sorption capacity of the bed $\left(K_{\mathrm{d}}\right.$ $\left.=Q_{\text {bed }} / C_{\text {inlet }}\right)$ and reflects the amount of HCF attached during the functionalization step. The fact that the $K_{\mathrm{d}}$ is highest for HCF@crushed-silica-monolith $\left(496 \mathrm{~mL} \cdot \mathrm{g}^{-1}\right)$ indicates that this sorbent contains the highest volume concentration of HCF. The sorbent with the steepest breakthrough curve and the highest 
bed efficiency $(90.8 \%$ ) was HCF@ silica-monolith, with the two other materials having more gradual breakthrough curves and BEs of about $83.4 \%$. The inlet concentration was reached more gradually at $V$ $>V_{R}$ for HCF@ silica-particles, probably because of the delayed diffusion of $\mathrm{Cs}^{+}$into the particles where the HCF is located.

Fig. 13b shows the breakthrough curves measured in a previous study of similar materials but at a lower Darcy velocity [10]. The bed efficiencies of HCF@ silica-monolith and HCF@ silica-particles were found to be $91 \%$ and $96 \%$, respectively. While HCF@ silica-monolith is as efficient for $\mathrm{Cs}^{+}$ removal at the two flow rates (BE 91\%), HCF@ silica-particles is substantially less efficient at faster flows $\left(\mathrm{BE}=96 \%\right.$ at $1 \mathrm{~m} \cdot \mathrm{h}^{-1}$ vs BE $=83.4 \%$ at $\left.8 \mathrm{~m} \cdot \mathrm{h}^{-1}\right)$. As for the RTDs (section 3.4.1) the values measured for HCF@crushed-silica-monolith are intermediate. Compared with HCF@ silica-monolith, the additional macropores between the crushed particles may create preferential flow paths.

From an industrial point of view, an ideal breakthrough is expected to avoid an early leakage of radionuclide, to maximize the sorption capacity of the column and to minimize the final waste volume.

(a) $-8 \mathrm{~m} \cdot \mathrm{h}^{-1}$

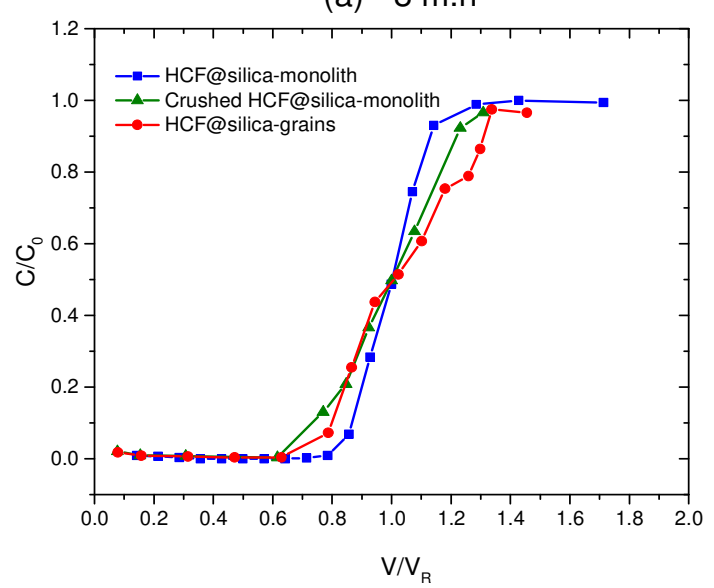

(b) $-1 \mathrm{~m} \cdot \mathrm{h}^{-1}$

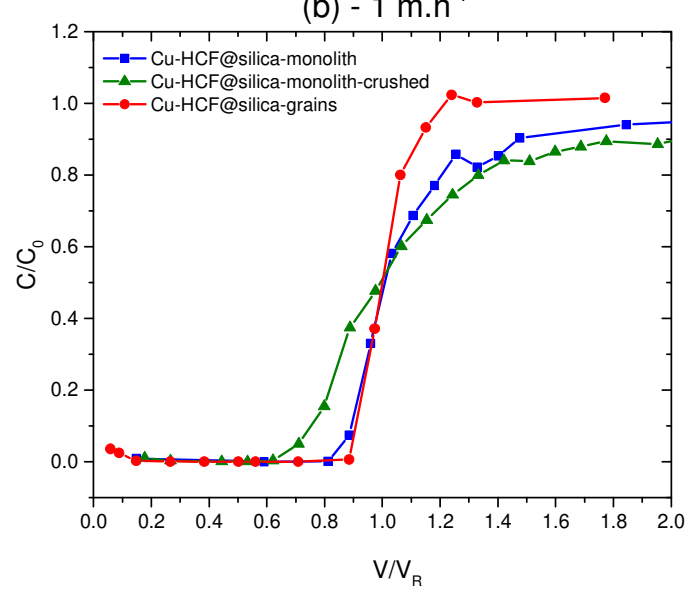

Fig. 13. Comparison of $\mathrm{Cs}^{+}$breakthrough curves measured for pristine and crushed silica monoliths functionalized with (a) $\mathrm{Cu} / \mathrm{K}$ and (b) $\mathrm{Cu}$ hexacyanoferrate nanoparticles (respectively HCF@crushed-silica-monolith, blue squares; and HCF@crushed-silica-monolith, green triangles) and commercial silica gel particles functionalized in the same way (HCF@silica-particles, red circles) with $\mathrm{Cs}^{+}$in mineral water $\left(2.6 \times 10^{-4} \mathrm{~mol} \cdot \mathrm{L}^{-1}\right)$ at a Darcy velocity of (a) $8 \mathrm{~m} \cdot \mathrm{h}^{-1}$ and $(\mathrm{b}) 1$ $\mathrm{m} \cdot \mathrm{h}^{-1}$. The data for part (b) are taken from Cabaud et al. [10]. 
Table 4

Breakthrough curve parameters for HCF@silica-monolith, crushed HCF@silica-monolith and HCF@silica-grains at a Darcy velocity of $8 \mathrm{~m} \cdot \mathrm{h}^{-1}$.

\begin{tabular}{|c|c|c|c|c|c|}
\hline Material & $\begin{array}{c}\text { Darcy velocity } \\
\left(\mathrm{m} \cdot \mathrm{h}^{-1}\right)\end{array}$ & $\begin{array}{l}\mathrm{m} \\
(\mathrm{g})\end{array}$ & $\begin{array}{c}\text { Qbed } \\
\left(\mathrm{mol} \cdot \mathrm{g}^{-1}\right)\end{array}$ & $\begin{array}{c}\mathrm{K}_{\mathrm{d}, \mathrm{Cs}} \\
\left(\mathrm{mL} \cdot \mathrm{g}^{-1}\right) \\
\end{array}$ & $\begin{array}{c}\text { Bed efficiency } \\
(\%)\end{array}$ \\
\hline Cu/K-HCF@silica-monolith & 8 & 0.518 & $5.17 \times 10^{-5}$ & 194 & 90.8 \\
\hline Cu/K-HCF@crushed-silica-monolith & 8 & 0.348 & $1.29 \times 10^{-4}$ & 496 & 83.4 \\
\hline Cu/K-HCF@silica-particles & 8 & 1.050 & $4.51 \times 10^{-5}$ & 169 & 83.3 \\
\hline Cu-HCF@silica-monolith ${ }^{\mathrm{a}}$ & 1 & 0.527 & $4.91 \times 10^{-5}$ & 196 & 91 \\
\hline Cu-HCF@crushed-silica-monolitha & 1 & 0.424 & $4.83 \times 10^{-5}$ & 194 & 83 \\
\hline Cu-HCF@silica-particles ${ }^{a}$ & 1 & 1.178 & $5.93 \times 10^{-5}$ & 259 & 96 \\
\hline
\end{tabular}

$\mathrm{HCF}$, hexacyanoferrate.

${ }^{\text {a}}$ Data from Cabaud et al. [10].

\subsubsection{Modeling of the breakthrough curves for HCF@ silica-monolith}

Fig. 14 shows the RTM of $\mathrm{Cs}^{+}$breakthrough through $\mathrm{HCF} @$ silica-monolith using the parameters listed in Table 1. A reference "immediate diffusion" model, with hydrodynamic dispersion but immediate diffusion through the skeleton and the aggregates is also reported for the sake of comparison. A noteworthy point is that the retention time is identical for the experimental and modeled curves, which means that the applied flow and the sorption capacity are correctly modeled. The immediate diffusion model produces very stiff breakthrough behavior, in spite of the dispersion, because of the strong immediate sorption of $\mathrm{Cs}^{+}$by the HCF. The full reactive transport model intercepts the experimental data and the immediate diffusion model when the outlet concentration reaches half of the inlet concentration $\left(C / C_{0}=0.5\right)$, but it fails to simulate both the slight early leakage (at $\left.C / C_{0}<0.5\right)$ and the more gradual leveling out of the breakthrough curve (at $C / C_{0}>0.5$ ). The full reactive transport model reproduces the non-ideal experimental data more precisely (Fig. 14), indicating that diffusion plays a key role in early leakage and the tail of the breakthrough curve. The gradient of the tail at two fifths of the height of the breakthrough curve is proportional to the corresponding fraction of the total sorption capacity reached at that point (40\%). Early leakage in the reactive transport model is due to $\mathrm{Cs}^{+}$ions passing through the macroporous channels without having had time to diffuse to the HCF. However, the fact that there is more leakage in the experiments suggests that there may be imperfections in the monoliths that are not considered in the model. Micro-cracks could not be completely discarded although they were not observed by SEM and the monoliths were carefully selected to minimize their 
occurrence. Another explanation is that the dispersion coefficient was fitted from the RTD experiments performed with the pure silica monolith before functionalization with HCF. That is to say the tortuosity of the silica monolith was taken into account. It probably underestimates the tortuosity of the actual monolith with the HCF nanoparticles used for Cs decontamination. This step-by-step method based on measured properties was found to be more generic and mechanistic that a direct empirical fit of the Cs breakthrough curve.

The tailing off of the upper half of the modeled breakthrough curve reflects the time taken by the $\mathrm{Cs}^{+}$ions to reach and saturate the HCF nanoparticles located in the deepest regions of the skeletal walls (Fig. 15). Additional simulations with different distributions of HCF between the two regions (Figs A.3-5) show that the experimental data are best reproduced with HCF in both the aggregate and the skeletal wall regions.

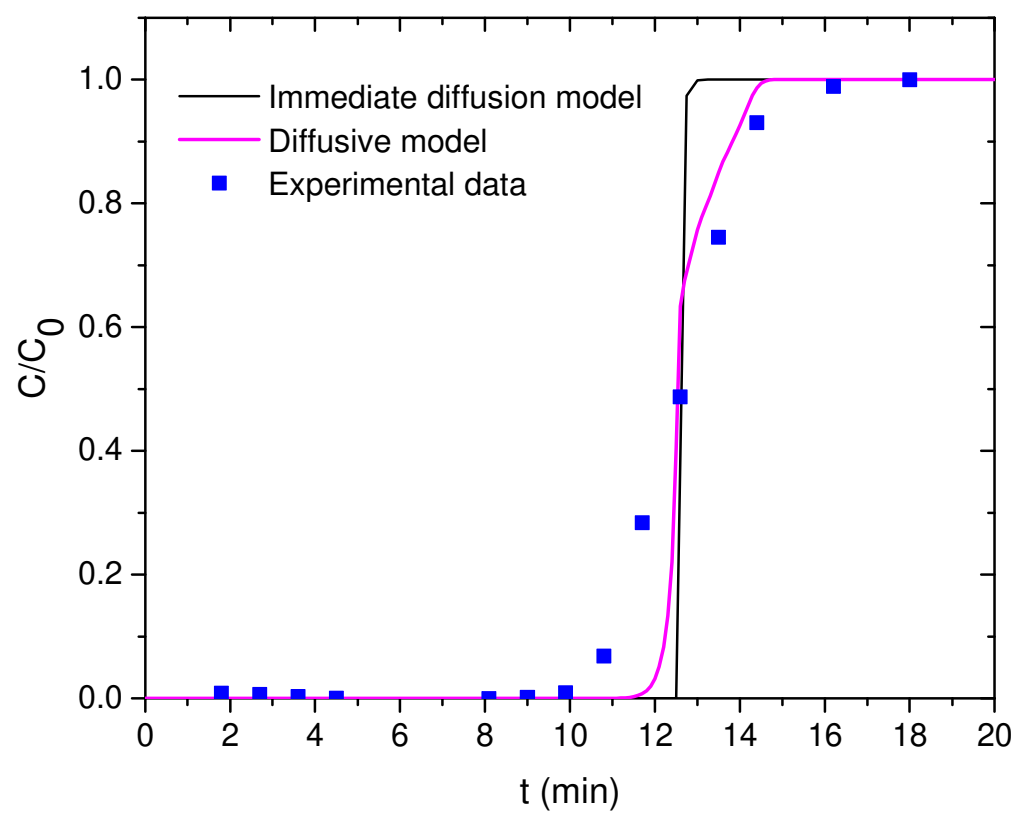

Fig. 14. Reactive transport modeling of the $\mathrm{Cs}^{+}$breakthrough curve for a silica monolith functionalized with $\mathrm{Cu} / \mathrm{K}$ hexacyanoferrate nanoparticles (HCF@ silica-monolith) a Darcy velocity of $8 \mathrm{~m} \cdot \mathrm{h}^{-1}$. The curve obtained with a model assuming immediate diffusion to all the HCF nanoparticles in the monolith is shown for comparison.

(a) 


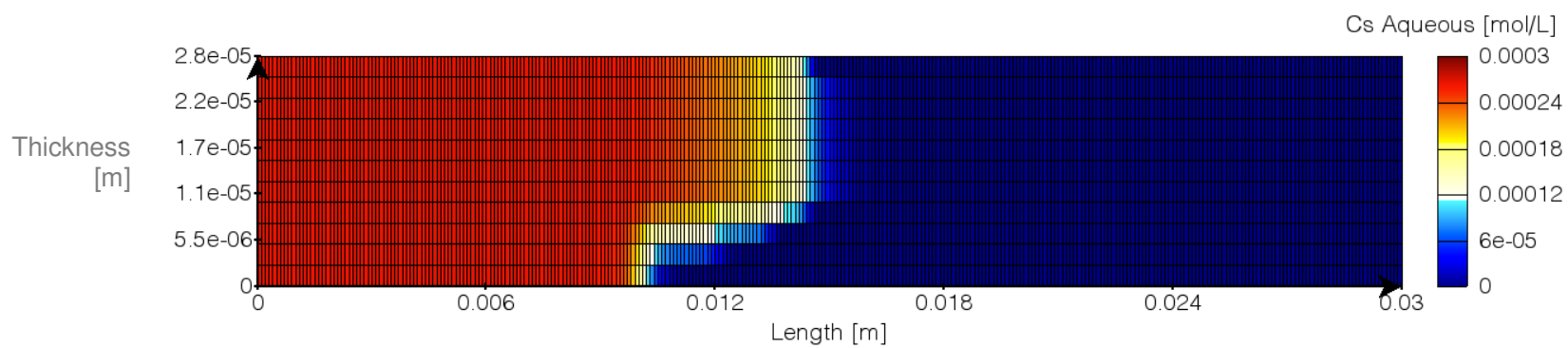

(b)

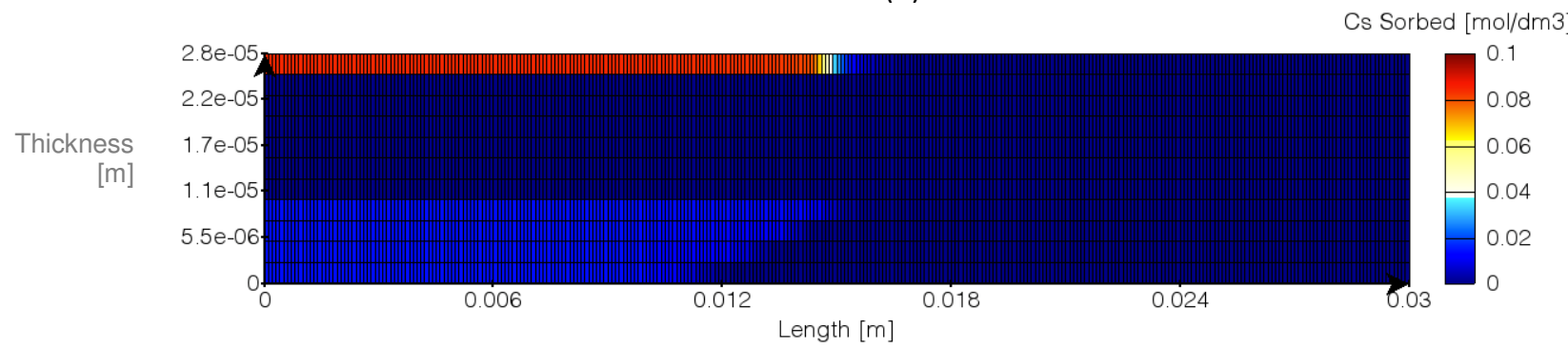

Fig. 15. (a) Aqueous and (b) sorbed concentrations of $\mathrm{Cs}^{+}$in the different regions of the reactive transport model of a silica monolith functionalized with $\mathrm{Cu} / \mathrm{K}$ hexacyanoferrate nanoparticles (HCF@ silica-monolith) after 6 min of a breakthrough experiment at a Darcy velocity of $8 \mathrm{~m} \cdot \mathrm{h}^{-1}$. The sorbed concentrations are given per $\mathrm{dm}^{3}$ of pore volume.

\section{Conclusions}

This study demonstrates the efficiency of three HCF-functionalized mesoporous silica materials for the removal of cesium from mineral water. The fast sorption kinetics and high selectivity for cesium over naturally present competing cations should prove valuable for column decontamination processes. The functionalized silica monolith was the material with the sharpest breakthrough front and its breakthrough behavior was found to remain close to ideal at a high Darcy velocity $\left(8 \mathrm{~m} \cdot \mathrm{h}^{-1}\right)$. The monolithic structure is able to sustain high flow rates without significant pressure loss. The sorption capacity of the material comes from easily accessible HCF nanoparticles located on the surface of the skeletal walls and to a lesser extent, within the mesopores inside the walls. In terms of methodology, this work highlights the value of measuring batch kinetics, RTDs and breakthrough curves in conjunction with RTM to characterize the sorption process in these materials.

The modeling results presented here for silica monoliths can be extrapolated to various experimental conditions or to other HCF-loaded materials or mixed sorbents, facilitating the design of future decontamination units. From an experimental perspective, hierarchical silica-based materials also have interesting chemical properties that make them transformable by thermal treatment into stable wastes forms [10]. Another promising avenue for further investigation may be adapting hierarchical 
silica monoliths to sequester multiple radionuclides [41]. The sorption properties of the silica monoliths could also be tailored for different applications using different treatments, for instance by forming a zeolite by local pseudomorphic transformation.

\section{Acknowledgements}

This work was supported by the CEA through the EDDEM project and by the U.S. Department of Energy, Office of Basic Energy Sciences, Division of Materials Sciences and Engineering [grant number DE-SC0016574 to the Center for Hierarchical Waste Form Materials, an Energy Frontier Research Center]. The authors also thank Fabrice Lorignon for his help setting up the RTD measurements.

\section{Appendix A. Supplementary material}




\section{References}

[1] C. Loos-Neskovic, S. Ayrault, V. Badillo, B. Jimenez, E. Garnier, M. Fedoroff, D.J. Jones, B. Merinov, Structure of copper-potassium hexacyanoferrate (II) and sorption mechanisms of cesium, Journal of Solid State Chemistry, 177 (2004) 1817-1828.

[2] P. Nielsen, B. Dresow, H.C. Heinrich, In vitro Study of 137Cs Sorption by Hexacyanoferrates(II), Journal of Chemical Sciences, 42 (1987) 1451-1460.

[3] G.B. Barton, J.L. Hepworth, E.D. McClanahan, R.L.M. J.r, H.H.V. Tuyl, Chemical Processing Wastes. Recovering Fission Products, Industrial \& Engineering Chemistry, 50 (1958) 212-216.

[4] C. Michel, Y. Barré, L. De Windt, C. de Dieuleveult, E. Brackx, A. Grandjean, Ion exchange and structural properties of a new cyanoferrate mesoporous silica material for Cs removal from natural saline waters, Journal of Environmental Chemical Engineering, 5 (2017) 810-817.

[5] C. Delchet, A. Tokarev, X. Dumail, G. Toquer, Y. Barré, Y. Guari, C. Guerin, J. Larionova, A. Grandjean, Extraction of radioactive cesium using innovative functionalized porous materials, RSC Advances, 2 (2012) 5707-5716.

[6] E.F.T. Lee, M. Streat, Sorption of Ceasium by Complex Hexacyanoferrates III. A study of the sorption Properties of Potassiupm Copper Ferrocyanide, Journal of Chemical Technology and Biotechnology, 33 (1983) 80-86.

[7] I.M. Ismail, M.R. El-Sourougy, N.A. Moneim, H.F. Aly, Preparation, characterization, and utilization of potassium nickel hexacyanoferrate for the separation of cesium and cobalt from contaminated waste water, Journal of Radioanalytical and Nuclear Chemistry, 237 (1998) 97-102.

[8] G.-R. Chen, Y.-R. Chang, X. Liu, T. Kawamoto, H. Tanaka, D. Parajuli, T. Kawasaki, Y. Kawatsu, T. Kobayashi, M.-L. Chen, Y.-K. Lo, Z. Lei, D.-J. Lee, Cesium removal from drinking water using Prussian blue adsorption followed by anion exchange process, Separation and Purification Technology, 172 (2017) 147-151.

[9] D. Enke, R. Gläser, U. Tallarek, Sol-Gel and Porous Glass-Based Silica Monoliths with Hierarchical Pore Structure for Solid-Liquid Catalysis, Chemie Ingenieur Technik, 88 (2016) 1561-1585.

[10] C. Cabaud, Y. Barré, L. De Windt, S. Gill, E. Dooryhée, M.P. Moloney, N. Massoni, A. Grandjean, Removing Cs within a continuous flow set-up by an ionic exchanger material transformable into a final waste form, Adsorption, (2019) 765-771.

[11] C.H. Pelisson, T. Nakanishi, Y. Zhu, K. Morisato, T. Kamei, A. Maeno, H. Kaji, S. Muroyama, M. Tafu, K. Kanamori, T. Shimada, K. Nakanishi, Grafted Polymethylhydrosiloxane on Hierarchically Porous Silica Monoliths: A New Path to Monolith-Supported Palladium Nanoparticles for Continuous Flow Catalysis Applications, ACS Appl Mater Interfaces, 9 (2017) 406-412.

[12] A. Sachse, R. Ameloot, B. Coq, F. Fajula, B. Coasne, D. De Vos, A. Galarneau, In situ synthesis of Cu-BTC (HKUST-1) in macro/mesoporous silica monoliths for continuous flow catalysis, Chem Commun (Camb), 48 (2012) 4749-4751.

[13] C.G. Frost, L. Mutton, Heterogeneous catalytic synthesis using microreactor technology, Green Chemistry, 12 (2010) 1687-1703.

[14] Y. Didi, B. Said, M. Micolle, T. Cacciaguerra, D. Cot, A. Geneste, F. Fajula, A. Galarneau, Nanocrystals FAU-X monoliths as highly efficient microreactors for cesium capture in continuous flow, Microporous and Mesoporous Materials, 285 (2019) 185-194.

[15] B. Fresco-Cala, S. Cardenas, M. Valcarcel, Preparation and evaluation of micro and meso porous silica monoliths with embedded carbon nanoparticles for the extraction of non-polar compounds from waters, J Chromatogr A, 1468 (2016) 55-63.

[16] M.M. Zheng, G.D. Ruan, Y.Q. Feng, Hybrid organic-inorganic silica monolith with hydrophobic/strong cation-exchange functional groups as a sorbent for micro-solid phase extraction, J Chromatogr A, 1216 (2009) 7739-7746.

[17] C. Vincent, A. Hertz, T. Vincent, Y. Barré, E. Guibal, Immobilization of inorganic ion-exchanger into biopolymer foams Application to cesium sorption, Chemical Engineering Journal, 236 (2014) 202-211.

[18] H. Mimura, M. Kimura, K. Akiba, Y. Onodera, Selective Removal of Cesium from Sodium Nitrate Solutions by Potassium Nickel Hexacyanoferrate-Loaded Chabazites, Separation Science and Technology, 34 (1999) 17-28.

[19] H. Mimura, M. Kimura, K. Akiba, Y. Onodera, Selective Removal of Cesium from Highly Concentrated Sodium Nitrate Neutral Solutions by Potassium Nickel Hexacyanoferrate(Ii)-Loaded Silica Gels, Solvent Extraction and Ion Exchange, 17 (2007) $403-417$.

[20] S. Milonjic, I. Bispo, M. Fedoroff, C. Loos-Neskovic, C. Vidal-Madjarc, Sorption of cesium on copper

hexacyanoferrate/polymer/silica composites in batch and dynamic conditions, Journal of Radioanalytical and Nuclear Chemistry, 252 (2002) 497-501.

[21] C. Michel, Y. Barré, M. Ben Guiza, C. de Dieuleveult, L. De Windt, A. Grandjean, Breakthrough studies of the adsorption of Cs from freshwater using a mesoporous silica material containing ferrocyanide, Chemical Engineering Journal, 339 (2018) 288-295.

[22] J. Causse, A. Tokarev, J. Ravaux, M. Moloney, Y. Barré, A. Grandjean, Facile one-pot synthesis of copper hexacyanoferrate nanoparticle functionalised silica monoliths for the selective entrapment of 137Cs, Journal of Materials Chemistry A, 2 (2014) $9461-9464$.

[23] K. Nakanishi, Pore Structure Control of Silica Gels Based on Phase Separation, Journal of Porous Materials, (1997) 67-112.

[24] A. Sachse, Synthèses de microréacteurs à base de monolithes siliciques et zéolithiques à porosité hiérarchique pour le développement de la catalyse en flux, in, Thèse de doctorat, École Nationale Supérieure de Chimie de Montpellier, 2011.

[25] A. Galarneau, A. Sachse, B. Said, C.-H. Pelisson, P. Boscaro, N. Brun, L. Courtheoux, N. Olivi-Tran, B. Coasne, F. Fajula, Hierarchical porous silica monoliths: A novel class of microreactors for process intensification in catalysis and adsorption, Comptes Rendus Chimie, 19 (2016) 231-247.

[26] A. Galarneau, Z. Abid, B. Said, Y. Didi, K. Szymanska, A. Jarzębski, F. Tancret, H. Hamaizi, A. Bengueddach, F. Di Renzo, F. Fajula, Synthesis and Textural Characterization of Mesoporous and Meso-/Macroporous Silica Monoliths Obtained by Spinodal Decomposition, Inorganics, 4 (2016) 9-34.

[27] J. Babin, J. Iapichella, B. Lefèvre, C. Biolley, J.-P. Bellat, F. Fajula, A. Galarneau, MCM-41 silica monoliths with independent control of meso- and macroporosity, New Journal of Chemistry, 31 (2007) 1907-1917.

[28] H.S. Fogler, Elements of Chemical Reaction Engineering, 4th edition ed., PHI, 2008.

[29] O. Levenspiel, Chemical reaction engineering, John Wiley \& Sons, Oregon State University, 1999.

[30] S. Whitaker, Advances in Theory of Fluid Motion in Porous Media, Industrial \& Engineering Chemistry, 61 (1969) 14-28.

[31] C.K. Rojas-Mayorga, A. Bonilla-Petriciolet, F.J. Sánchez-Ruiz, J. Moreno-Pérez, H.E. Reynel-Ávila, I.A. Aguayo-Villarreal, D.I. Mendoza-Castillo, Breakthrough curve modeling of liquid-phase adsorption of fluoride ions on aluminum-doped bone char using microcolumns: Effectiveness of data fitting approaches, Journal of Molecular Liquids, 208 (2015) 114-121. 
[32] J. van der Lee, L. De Windt, V. Lagneau, P. Goblet, Module-oriented modeling of reactive transport with HYTEC, Computers \& Geosciences, 29 (2003) 265-275.

[33] T. Wolery, EQ3/6, A software package for geochemical modelling of aqueous systems: package overview and installation guide (version 7.0), Lawrence Livermore National Laboratory, USA, 1992.

[34] E.L. Cussler, Diffusion: Mass Transfer in Fluids Systems, Cambridge University Press, 2009.

[35] A.I. Liapis, J.J. Meyers, O.K. Crosser, Modeling and simulation of the dynamic behavior of monoliths: Effects of pore structure from pore network model analysis and comparison with columns packed with porous spherical particles, journal of chromatography A, 865 (1999) 13-25.

[36] M. Zabka, M. Minceva, A.E. Rodrigues, Experimental characterization and modelling of analytical monolithic column, J Biochem Biophys Methods, 70 (2007) 95-105.

[37] Y.L. Li, B.D. Zeidman, S.Y. Hu, C.H. Henager, T.M. Besmann, A. Grandjean, A physics-based mesoscale phase-field model for predicting the uptake kinetics of radionuclides in hierarchical nuclear wasteform materials, Computational Materials Science, 159 (2019) 103-109.

[38] K.S. Hwang, C.W. Parka, K.W. Leea, S.J. Parkb, H.M. Yanga, Highly efficient removal of radioactive cesium by sodium-copper hexacyanoferrate-modified magnetic nanoparticles, Colloids and Surfaces A, 516 (2017) 375-382.

[39] C. Michel, Y. Barré, C. de Dieuleveult, A. Grandjean, L. De Windt, Cs ion exchange by a potassium nickel hexacyanoferrate loaded on a granular support, Chemical Engineering Science, 137 (2015) 904-913.

[40] D. Alby, C. Charnay, M. Heran, B. Prelot, J. Zajac, Recent developments in nanostructured inorganic materials for sorption of cesium and strontium: Synthesis and shaping, sorption capacity, mechanisms, and selectivity-A review, J Hazard Mater, 344 (2018) $511-530$. [41] H.-C. zur Loye, T. Besmann, J. Amoroso, K. Brinkman, A. Grandjean, C.H. Henager, S. Hu, S.T. Misture, S.R. Phillpot, N.B. Shustova, H. Wang, R.J. Koch, G. Morrison, E. Dolgopolova, Hierarchical Materials as Tailored Nuclear Waste Forms: A Perspective, Chemistry of Materials, 30 (2018) 4475-4488. 